\title{
Study of the critical values of breakdown voltage for different gases
}

Salman Hamza Hussein

Veterinary Medicine College, Al-Qadisiyah University, Public Health Department. salmanhamza@qu.edu.iq

Received:-21/21/2017

Accepted:-21/1/2018

\begin{abstract}
In this paper we study the critical values of the $p d$ (gas pressure $\times$ electrode distance) and breakdown voltage dependency on effective secondary emission coefficient $\gamma$. These values are calculated for different gases $\left(\mathrm{H}_{2}, \mathrm{~N}_{2}, \mathrm{Air}, \mathrm{H}_{2} \mathrm{O}, \mathrm{Hg}, \mathrm{He}, \mathrm{Ne}, \mathrm{Ar}, \mathrm{Kr}\right.$ and $\left.\mathrm{Xe}\right)$. The critical values of the $p d$ and breakdown voltage decreased with effective secondary emission coefficient $\gamma$ for all these gases
\end{abstract}

Key word: Breakdown voltage, Effective secondary emission coefficient, Paschen curve, Electrical discharge

Phisiology Classification QC71706-71808 


\section{Introduction}

The discharge voltage in the process of electrical breakdown is very important in various electrical discharges of plasma and industrial applications [1-8]. The breakdown voltage represented by Paschen curve or Paschen law which is the relation between breakdown voltage and $p d$ (gas pressure $\times$ electrode distance) [9]. In this work; the critical values of breakdown voltage have been studied with critical values of $p d$ (the discharge occur at this value of $p d$ ) in Townsend discharge for rare gases and other gases. In this type of discharges; there are no light or spark, therefore is called dark discharge.

The problem can be describe by two electrodes with distance $d$ inside vessel filling with a gas connected to DC power supply as shown in figure (1). The mechanism of Townsend ionization can be characterized by exponentially growth in the numbers of electrons inside vessel. These electrons come from two avalanches. The first avalanche occur when an electrons emitted from the cathode surface by starting electrons impacted the cathode. The processes collisions between emitted electrons and neutral gas atoms released secondary electrons called $\alpha$-electrons respect to the first Townsend coefficient or ionization Townsend coefficient $\alpha$ (which can be define as the number of electronion pairs created by a single electron in unit length and its depend on intensity of electric field, the pressure of gas and type of gas). The second avalanche occur when the ions which created in the first avalanche bombarded the surface of cathode that lead to emit electrons called $\gamma$-electrons respect to the second Townsend coefficient or secondary electron emission coefficient $\gamma$ ((which can be defined as the number of secondary electrons from the surface of cathode to the number of ions bombarded the surface of cathode and its depend on the type of the material of cathode, gas pressure, applied electric field $E$, type of gas and distance between electrodes[10,11].

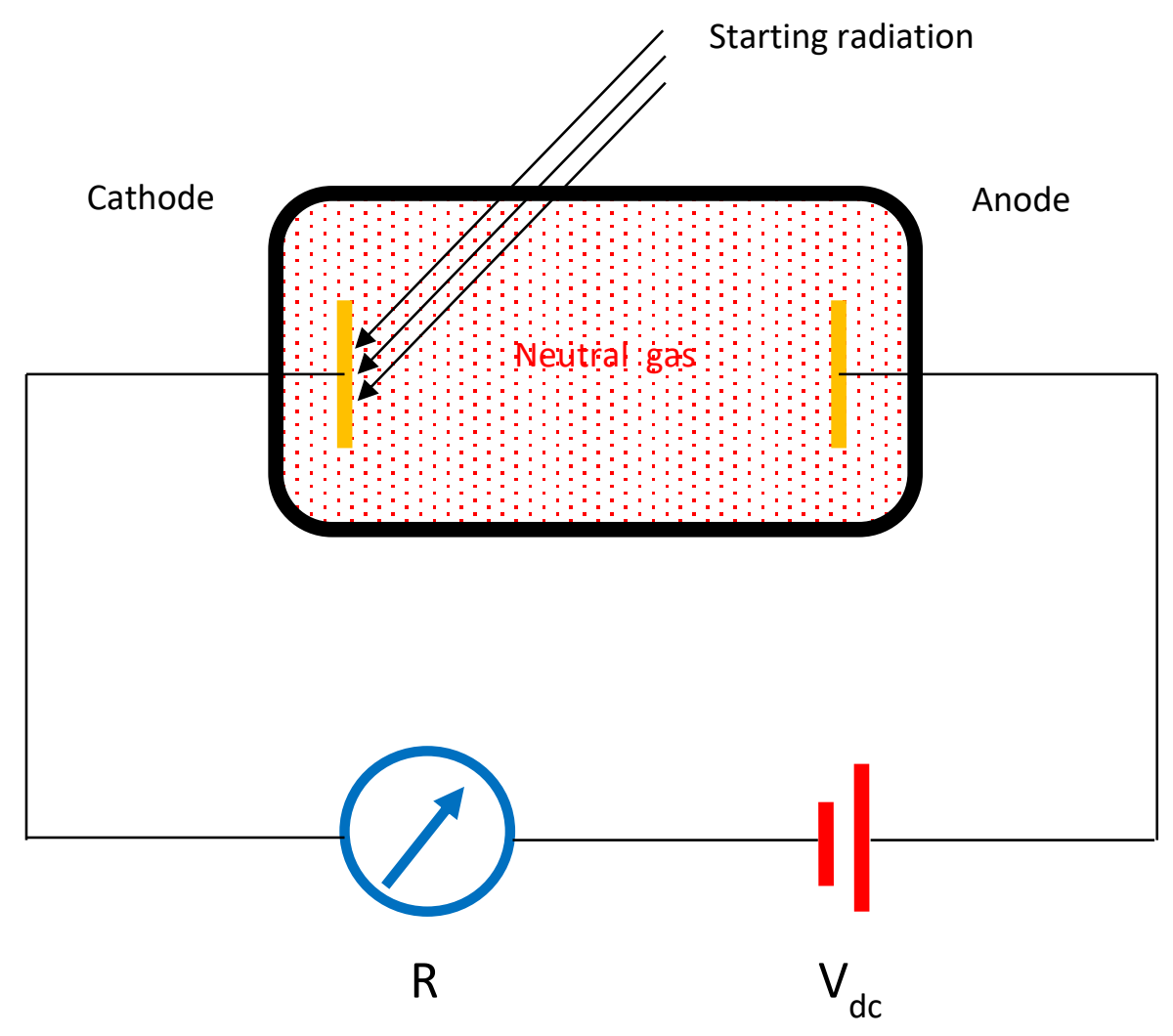


Figure (1): Schematic of the problem illustrated the neutral gas inside vessel which contains two electrodes connected to power supply

\section{Theoretical treatment}

The first Townsend coefficient $\alpha$ as a function of applied electric field and gas pressure is given by well-known equation,

$\alpha(E / p)=A p e^{-B \frac{p}{E}}$

Where $E$ is the electric field and $p$ is the gas pressure; $A$ and $B$ are constants depend on the type of gas and listed in table (1) [12].

The electric field related to the breakdown voltage $V_{b}$ and the distance between electrodes $d$ in the following equation,

$E=\frac{V_{b}}{d}$

By using equation (2), rewrite equation (1) to be in the following form

$\frac{\alpha}{p}=A e^{-B \frac{p d}{V_{b}}}$

Table (1): The values of $A$ and $B$ [12].

\begin{tabular}{|l|l|l|}
\hline gas & $\begin{array}{c}\text { A } \\
\text { cm }^{-1} \text { Torr }^{-1}\end{array}$ & $\begin{array}{c}\text { B } \\
\text { Vcm }^{-1} \text { Torr }^{-1}\end{array}$ \\
\hline $\mathrm{He}$ & 3 & 34 \\
\hline $\mathrm{Ne}$ & 4 & 100 \\
\hline $\mathrm{Ar}$ & 12 & 180 \\
\hline $\mathrm{Kr}$ & 17 & 240 \\
\hline $\mathrm{Xe}$ & 26 & 350 \\
\hline $\mathrm{N}_{2}$ & 12 & 342 \\
\hline $\mathrm{H}_{2}$ & 5 & 130 \\
\hline $\mathrm{Air}$ & 15 & 365 \\
\hline $\mathrm{CO}_{2}$ & 20 & 466 \\
\hline $\mathrm{H}_{2} \mathrm{O}$ & 13 & 290 \\
\hline
\end{tabular}

The second Townsend coefficient related to the first Townsend coefficient in a famous relation was driven by Townsend [9]: $\alpha=\frac{1}{d} \ln \left(1+\frac{1}{\gamma}\right)$

By substituting the value of $\alpha$ into equation (3) to be in the following form:

$\frac{\ln \left(1+\frac{1}{\gamma}\right)}{p d}=A e^{-B \frac{p d}{V_{b}}}$

Equation (5) simplifies to get the breakdown voltage as a function of $p d$;

$V_{b}=B p d\left[1 / \ln \left(\frac{A p d}{\ln \left(1+\frac{1}{\gamma}\right)}\right)\right]$

\section{I-calculation of the critical value of pd}

To calculate the critical value of $p d$ we must be find the fist derivative to the breakdown voltage, where

$\frac{d V_{b}}{d(p d)}=0 \Rightarrow p d=(p d)_{\text {critical }}$

Let $\quad x=p d \quad \ldots(7 a)$,

and $\quad R=\ln \left(1+\frac{1}{\gamma}\right)$

by using equations (7); we can write equation (6) in the form:

$V_{b}=\frac{B x}{\ln \left(\frac{A}{R} x\right)}$

Differentiate equation (8) with respect to $x$ to get;

$\frac{d V_{b}}{d x}=\frac{B \ln \left(\frac{A}{R} x\right)-B}{\left(\ln \left(\frac{A}{R} x\right)\right)^{2}}$

At $\frac{d V_{b}}{d x}=0$; we get the minimum breakdown voltage at the critical value of $p d\left[\left(V_{b}\right)_{\min }\right.$ is also called as the minimum 
spark potential]. Therefore from equation (9) we can get;

$\ln \left(\frac{A}{R} x\right)=1$

By inserting equations (7) into equation (10), we get;

$\ln \left(\frac{A(p d)_{\text {critical }}}{\ln \left(1+\frac{1}{\gamma}\right)}\right)=1$

Take the exponential to the both side of above equation; we can get the critical value of $p d$ as a function to the second Townsend coefficient $\gamma$ in the following relation

$(p d)_{\text {critical }}=\frac{2.718}{A} \ln \left(1+\frac{1}{\gamma}\right)$

II- Calculation of the critical value of $V_{b}$ as a function of $\gamma$

It is simple to find a relation between critical values as a function of the second Townsend coefficient by using equation (12) into equation (6) to get the following relation;
$\left(V_{b}\right)_{\text {critical }}=\frac{B}{A} 2.718 \ln \left(1+\frac{1}{\gamma}\right) \ldots$

\section{Results and discussion}

The critical values of the $p d$ calculated from equation (12), represented in figure (2) for rare gases and figure (3) for other gases. These figures illustrated that all values decrease with $\gamma$. The critical values of the $V_{b}$ calculated from equation (13), represented in figure (4) for rare gases and figure (5) for other gases. These figures illustrated that all values decrease with ESEC. The factor $\ln \left(1+\frac{1}{\gamma}\right)$ in equations (12) and equation (13) is proportional inversely with $\gamma$ and that reflected on the critical values of the $p d$ and breakdown voltage. For low values of ESEC, the number of secondary electron emission from cathode surface are decrease due to the impact ions, therefore the number of collisions of electrons with the neutral gases also decrease that lead to increase the breakdown voltage. 


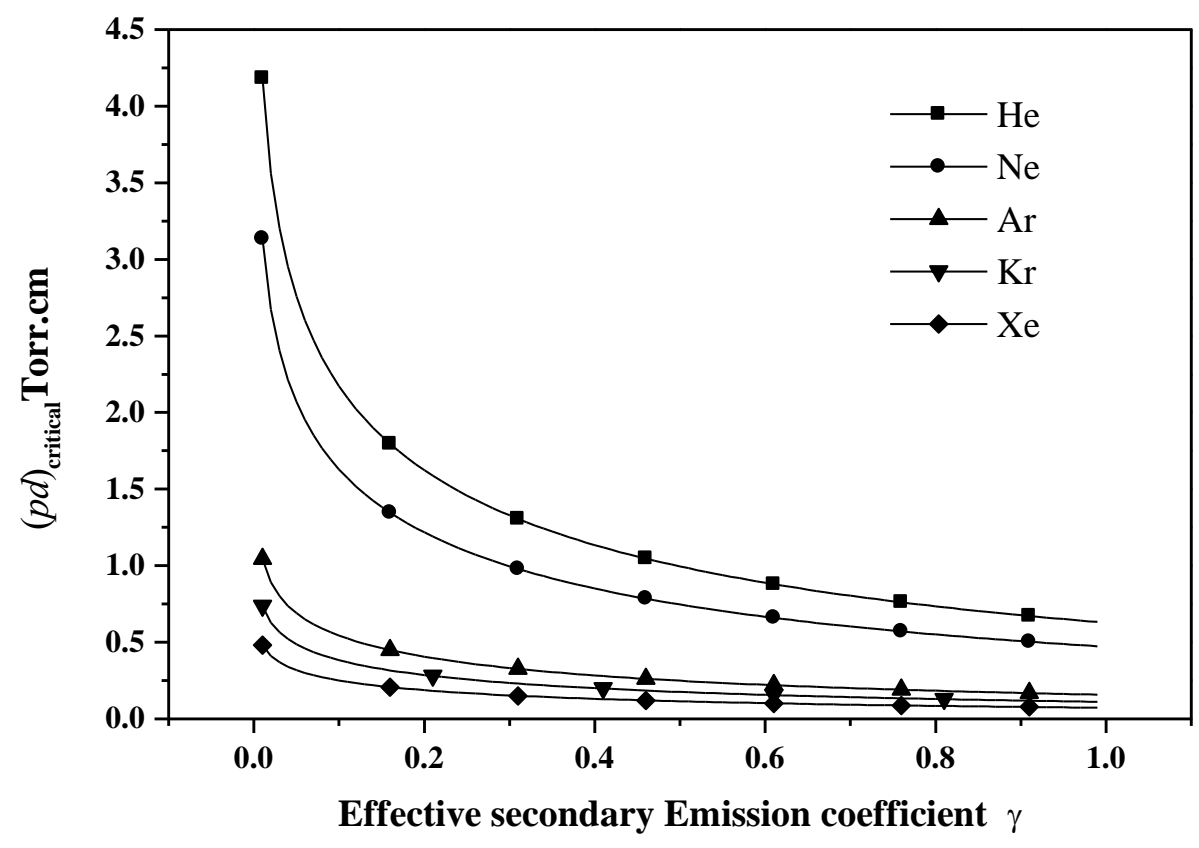

Figure (2): The critical values of the $p d$ (Torr.cm) as a function of $\gamma$ for rare gases.

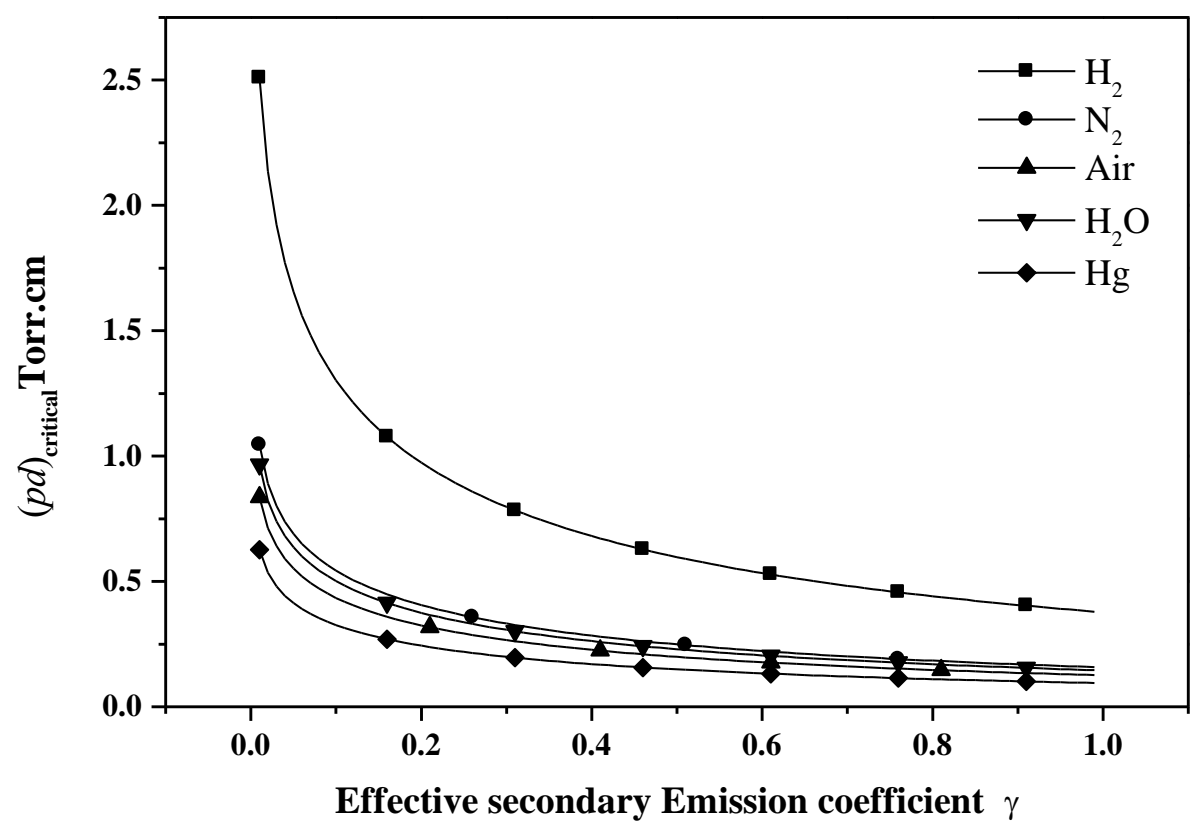

Figure (3): The critical values of the $p d$ (Torr.cm) as a function of $\gamma$ for other gases. 


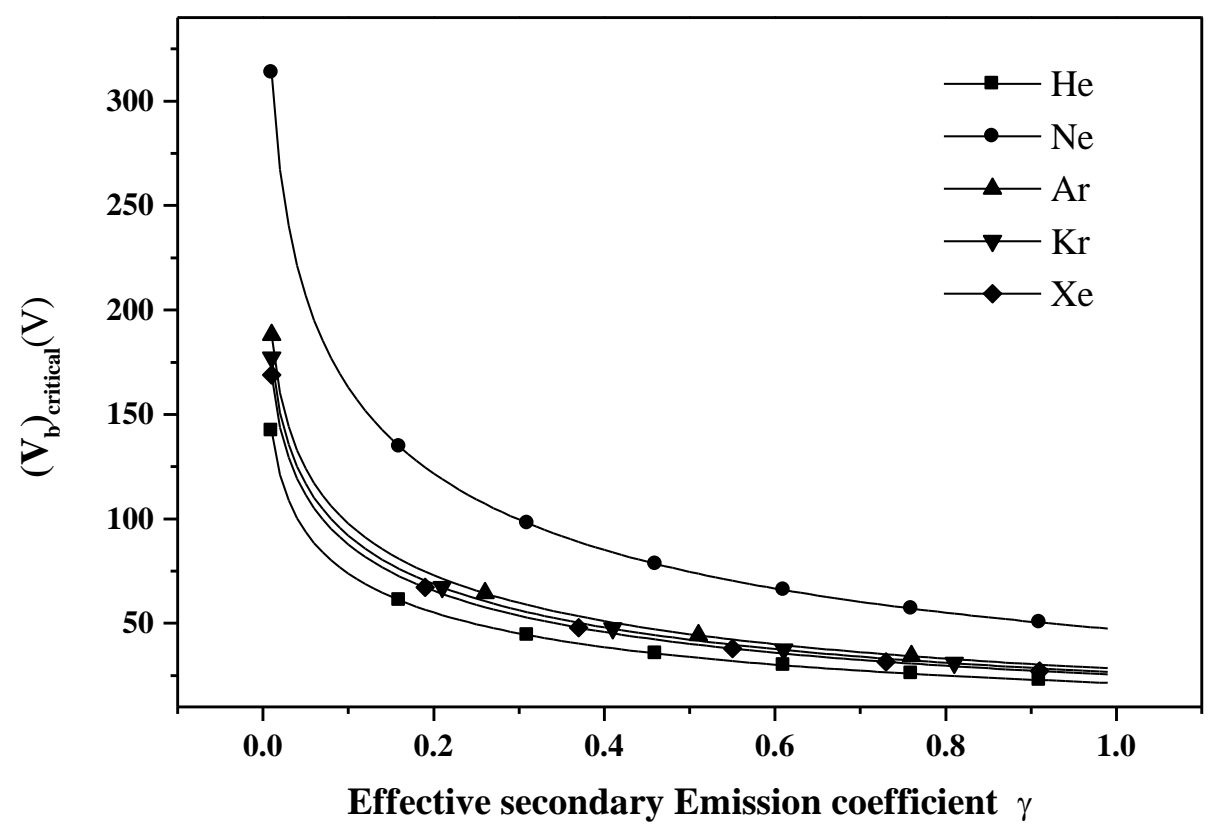

Figure (4): The critical values of the $V_{b}(\mathrm{~V})$ as a function of $\gamma$ for rare gases.

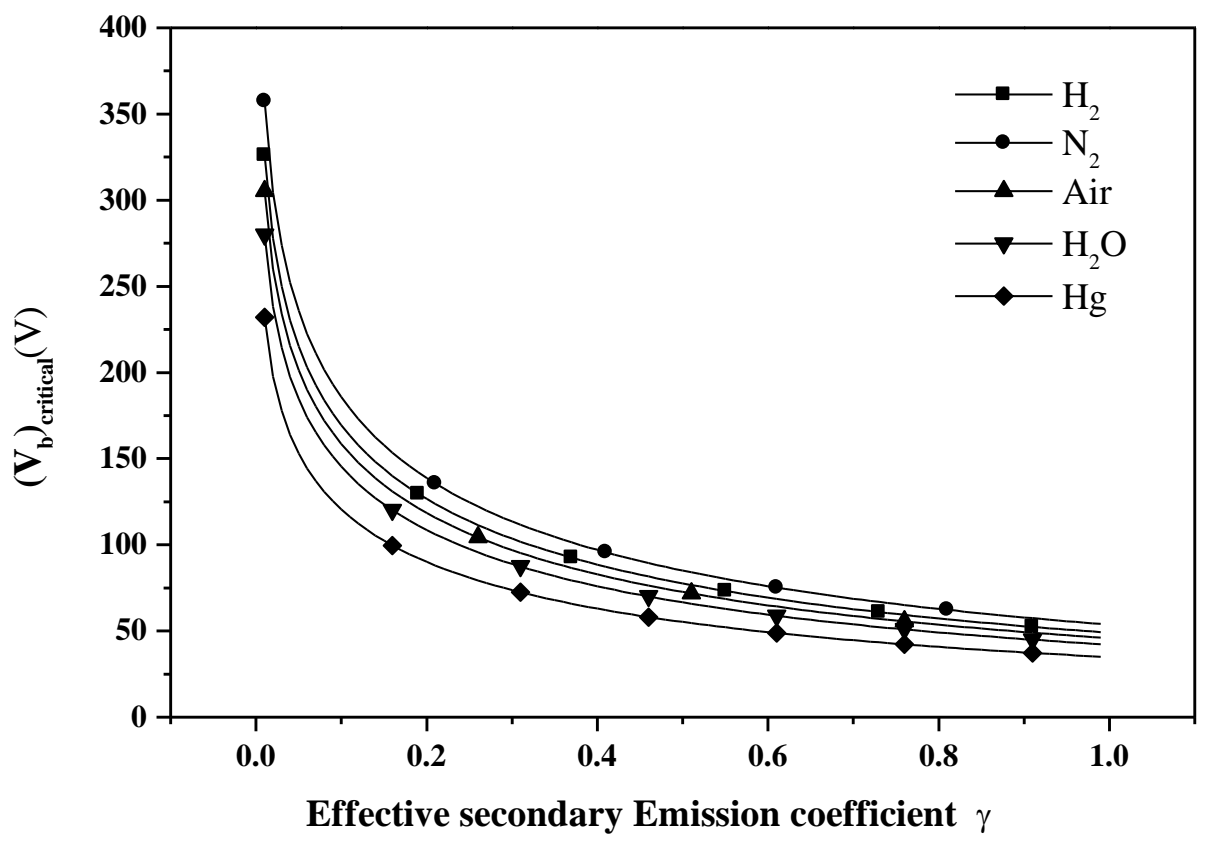

Figure (5): The critical values of the $V_{b}(\mathrm{~V})$ as a function of $\gamma$ for other gases. 


\section{Conclusions}

The critical values of the $p d$ and breakdown voltage decreased with effective secondary emission coefficient $\gamma$ for all studied gases according to the term $\ln \left(1+\frac{1}{\gamma}\right)$.

\section{References}

1- R. W. Engstrom and W. S. Huxford, "Time-Lag Analysis of the Townsend Discharge in Argon with Activated Caesium Electrodes", Phys. Rev. 58, 67, (1940).

2- R. R. Newton, "Transients in Townsend Discharges", Phys. Rev. 73, 570, (1948).

3- N. N. Trofimchuk, M. P. Lorikyan, R. L. Kavalov, A. N. Arvanov, and V. G. Gavalyan. "The mechanism of controlled secondary electron emission". SOV. Phys.-JETP, Vol. 42, No.2, (1975).

4- O. Sahni and C. Lanza, "Influence of the secondary electron emission coefficient of argon on Paschen breakdown curves in ac plasma panels for neon $+0.1 \%$ argon mixture", J. App. Phys., 47, 5107, (1976).

5- V A Lisovskiy, S D Yakovin and V D Yegorenkov "Low- pressure gas breakdown in uniform dc electric field". J. Phys. D: Appl. Phys. 33 (2000).

6- A. N. Tkachev and S. I. Yakovlenko, "The Townsend coefficient and electron runaway characteristic in Nitrogen",
Technical physics letters, Vol. 30, No. 4. (2004)

7- M. Radmilovic'-Radjenovic, B. Radjenovic', Ž $Z^{\sim}$ Nikitovic', $\breve{S}$. Matejc ik and M. Klas." The humidity effect on the breakdown voltage characteristics and the transport parameters of air", Nuclear Instruments and Methods in Physics Research, B 279, (2012).

8- Bahaa T. Chiad1, Firas J. Kadhim1 and Ahmed A. Anber. "Study the Addition Of Lab-Made Gas Mixing Unit with Varying of Inter-Electrode Distances on the Characterization of DC Magnetron Sputtering System". Open Access Library Journal, Volume 4, e3269 (2017).

9- G. Auday, Ph. Guillot, J. Galy, and H. Brunet, " Experimental study of the effective secondary emission coefficient for rare gases and copper electrodes", J. Appl. Phys., Vol. 83, No. 11, (1998).

10- V. P. Nagorny and P. J. Drallos," Effective secondary emission coefficient in a high-pressure noble gas", Plasma Sources Sci. Technol. 6 (1997).

11- H. Noori and A. H. Ranjbar,"A theoretical approach to electric breakdown behavior and effective secondary emission coefficient in gas discharge process between two parallel-plane disk electrodes", $\quad \mathrm{J}$. Appl. Phys. 112, 023301 (2012).

12- Y. P. Raizer, "Gas Discharge Physics", Springer, New York, (1991). 


\section{دراسة القيم الحرجة لفولتية الانهيار لغازات مختلفة \\ سلمان حمزة حسين \\ كلية الطب البيطري-جامعة القادسية \\ salmanhamza@qu.edu.iq}

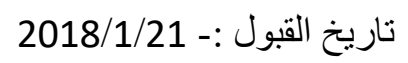

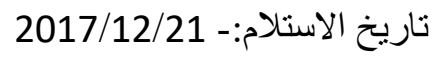

\section{الخلاصة}

في هذا البحث تمت دراسة اعتمادية القيم الحرجة لكل من مd (ضغط الغاز × المسافة

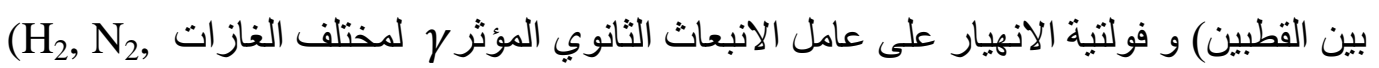
Air, $\mathrm{H}_{2} \mathrm{O}, \mathrm{Hg}, \mathrm{He}, \mathrm{Ne}, \mathrm{Ar}, \mathrm{Kr}$ and Xe) الانهيار تتناقص مع زيادة $\gamma$ لجميع هذه الغاز ات.

كلمات مفتاحية: فولتية الانهيار، عامل الانبعاث الثانوي المؤثر، منحنى باثن، التفريغ الكهربائي 